\title{
La restauración de las pinturas murales de La Moreña, La Barca, Jalisco: intervenciones, resultados y reflexiones parciales en torno de un proyecto de la ENCRyM-INAH
}

\author{
Sergio Arturo Montero Alarcón \\ Rosa Liliana Alfaro Martínez
}

os murales conocidos como La Moreña decoran los paramentos interiores de la actual casa de cultura del municipio de La Barca, Jalisco, México (dependencia de la Secretaría de Cultura del estado) (Figura 1), una construcción que data del siglo XVIII localizada en la esquina de la calle Juárez y el Portal Independencia, al sur de la plaza de armas de la población de La Barca (Figura 2).

Las pinturas murales, que abarcan una extensión aproximada de $427 \mathrm{~m}^{2}$, fueron elaboradas entre 1855 y 1867 siguiendo la técnica de óleo sobre aplanado de cal por un autor aún no identificado (Montero 1991:27). Se trata de un programa pictórico de 19 imágenes: trece decoran el corredor del patio y las restantes en los dos pasillos de la antigua casa (Figura 3).

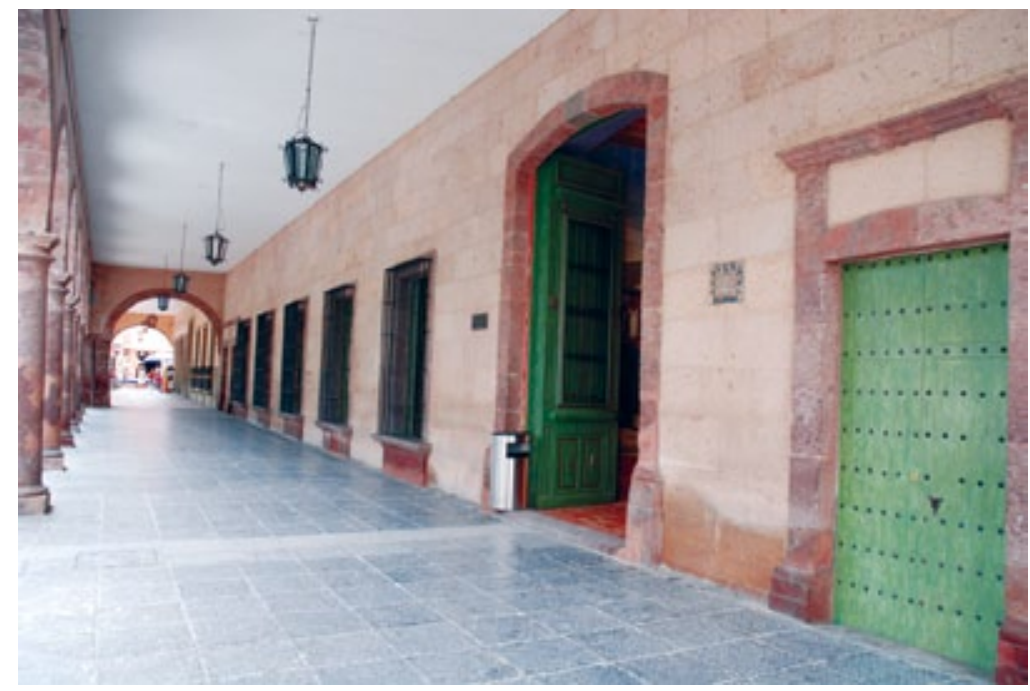

FIGURA 1. Casa de cultura de La Moreña (Fotografía: Gerardo Ruiz Hellión, 2008; cortesía: ENCRyM-INAH). 


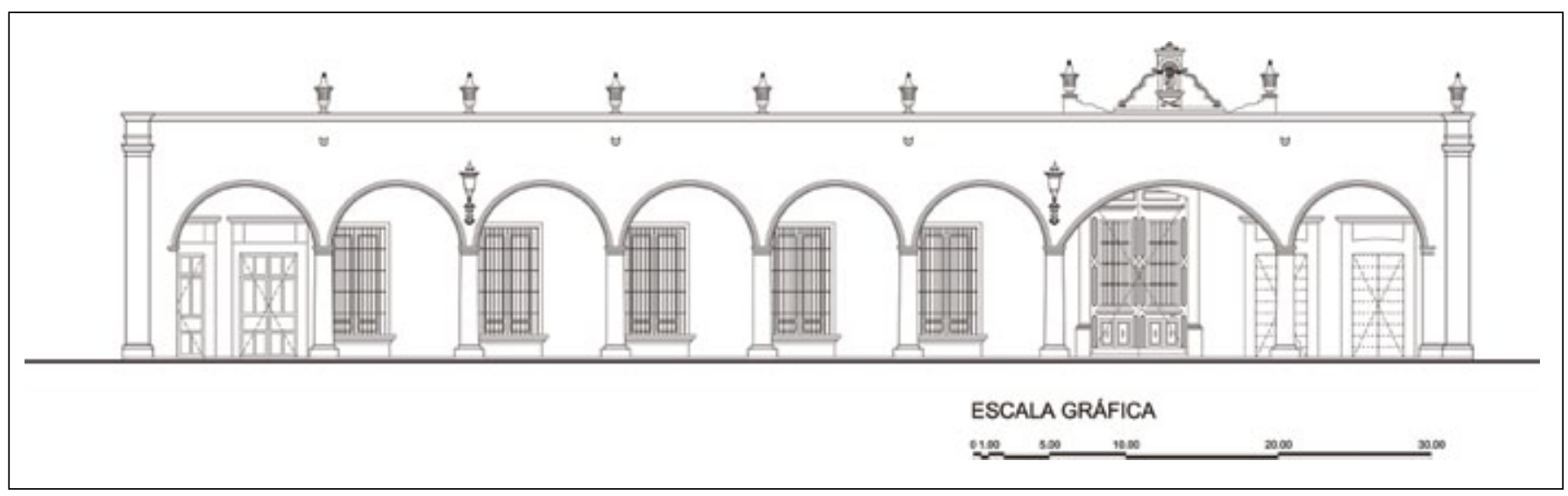

FIGURA 2. Fachada principal de La Moreña (Dibujo: Oscar Ibarra Vega 2010; cortesía: ENCRyM-INAH).

Todas ellas plasman escenas costumbristas del México decimonónico, que en su mayoría se basaron en las estampas publicadas en el libro México y sus alrededores editado por Pietro Gualdi en la casa litográfica del señor Decaen, que apareció por primera vez en prensa en 1855 (Figura 4), realizadas principalmente por el dibujante Casimiro Castro, aunque también participaron pintores como Julián Campillo, G. Rodríguez y Luis Auda (Castro 2010).

En el año 2007, la Escuela Nacional de Conservación, Restauración y Museografía (ENCRyM) del Instituto Nacional de Antropología e Historia (INAH) inició un proyecto para la conservación y restauración de las pinturas murales de La Moreña bajo la dirección del profesor Sergio Arturo Montero Alarcón (ENCRyM-INAH) y la coordinación de la licenciada Gisela García Correa de la Escuela de Conservación y Restauración de Occidente (ECRO). El presente reporte expone las labores y los resultados de la segunda temporada de trabajo, que tuvo lugar entre febrero y diciembre del año 2009, en la que se abordaron interesantes problemáticas de alteración que exigieron soluciones de conservación específicas.

\section{Importancia de las pinturas murales de La Moreña}

Dos son los principales ámbitos de valoración mediante los que deter-

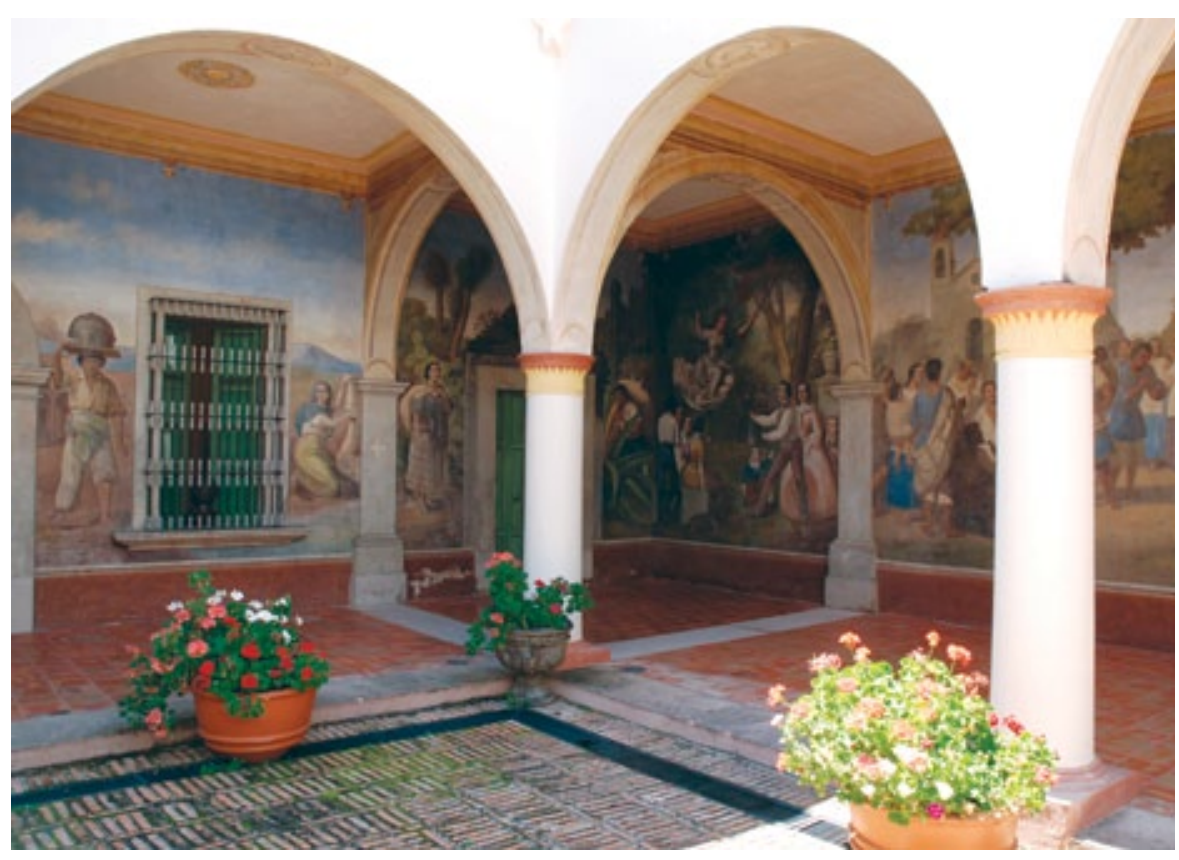

FIGURA 3. Murales ubicados en el corredor del patio (Fotografía: Gerardo Ruiz Hellión, 2008; cortesía: ENCRyM-INAH).

minamos la importancia de las pinturas murales de La Moreña: el estético y el histórico.

Para entender sus valores estéticos es necesario conocer el contexto artístico en el que se elaboraron estas obras: efectivamente, su factura se ubica en una época —-mediados del siglo XIX- en que la Academia de San Carlos, institución entonces dirigida por Pelegrín Clavé, establecía las principales tendencias estéticas.

Ahí el arte se interpretaba en ese momento, según Bernardo Couto (Gutiérrez 2000), como un vehículo de unidad nacional. Su objeto era, por tanto, crear un sentido de identidad del ser mexicano a través del énfasis en temas nacionalistas, lo que se manifestaba en tres tendencias: la primera era la representación de escenas históricas sobre la conquista y el México prehispánico, que inspiraban un especial orgullo liberal (Ramírez 2000ab); una segunda vertiente, de naturaleza conservadora, enfatizaba la selección de pasajes bíblicos (Gutiérrez 2000) y, en tercer lugar, la pintura paisajista, por su parte, fomentaba el orgullo nacional a partir de la difusión de escenas rurales, apoyándose en el desarrollo de la cartografía y la geografía. 


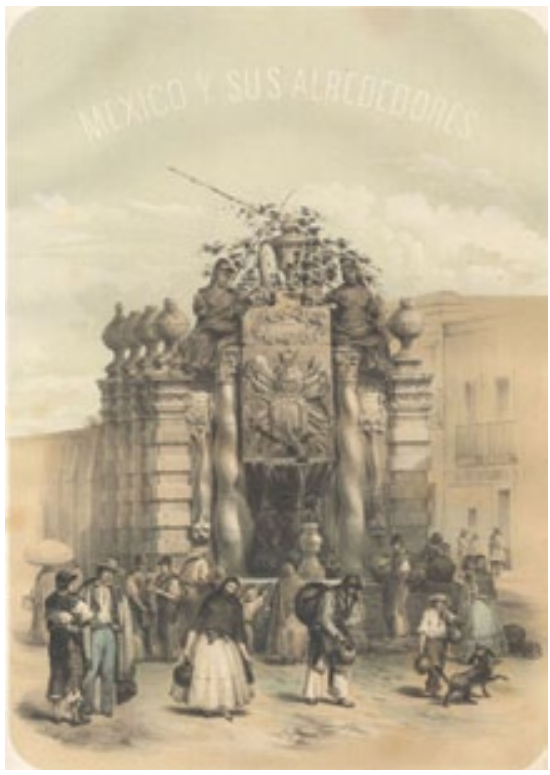

FIGURA 4. Estampa de Casimiro Castro (Fuente: Biblioteca Nacional-Hemeroteca Naciona /Biblioteca Virtual Miguel de Cervantes), disponible en [http://www.lluisvives.com/servlet/ SirveObras/mex/014728486557949177 54480/thm0001.htm]
La temática costumbrista de los murales de La Moreña ciertamente parece muy alejada de esas tendencias promovidas oficialmente. De hecho, esta singularidad es lo que le confiere un valor especial, ya que su representación deja a un lado los cánones académicos para inspirarse, en cambio, en las mencionadas estampas de Casimiro Castro, un artista que si bien no había egresado de la Academia, ganó fama como cronista pictórico, gracias a la documentación de paisajes y escenas de costumbres mexicanas propias de su época.

Desde el punto de vista artístico, en la copia de las estampas que le sirvieron de inspiración son evidentes la gran habilidad y la maestría técnica mostradas por el autor de las pinturas de La Moreña, tanto en el manejo de veladuras y empastes al óleo, como en el uso de una paleta cromá- tica que, además de abarcar matices desde el rojo, ocre y tierra hasta el verde y azul, combina colores saturados y vivos, lo que sugiere que tenía conocimientos sólidos sobre técnicas pictóricas, e incluso que posiblemente hubiese sido egresado de la propia Academia de San Carlos (Figura 5).

Las pinturas son notables, asimismo, en el desarrollo de un marcado estilo naturalista: aunque hay que reconocer que ciertos detalles resultan caricaturescos (por ejemplo, algunos personajes y animales carecen de proporción armónica en relación con el resto de la composición), son pormenores que, al parecer, provienen de la copia de defectos que ya aparecían en las estampas originales.

Adicionalmente, las escenas plasmadas en La Moreña pueden considerarse como un documento histórico de gran relevancia, pues
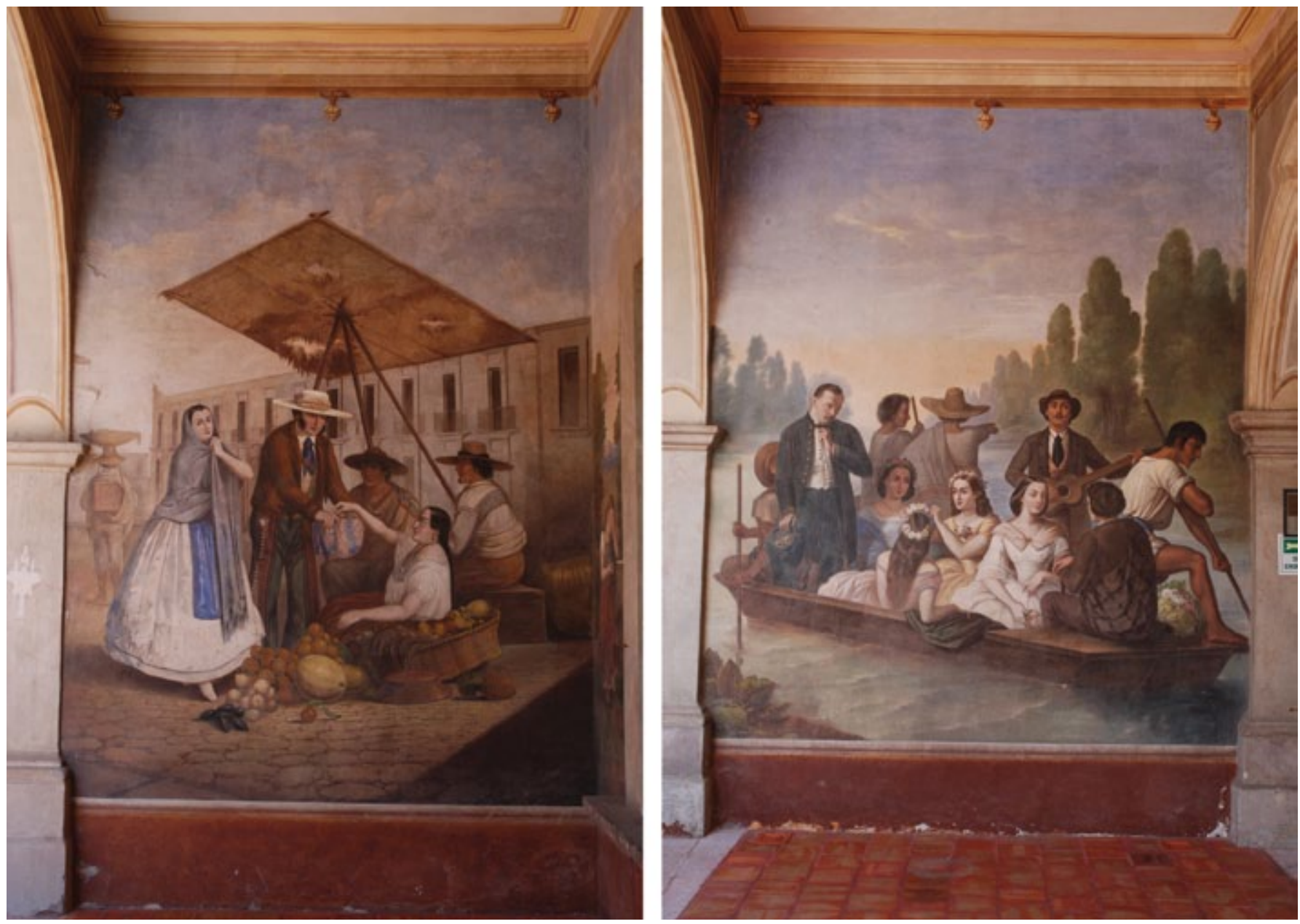

FIGURA 5. Algunas escenas plasmadas en los murales de La Moreña (Fotografía: Gerardo Ruiz Hellión, 2008; cortesía: ENCRyM-INAH). 
representan costumbres y situaciones, tanto rurales como citadinas, de la sociedad decimonónica mexicana; constituyen, siguiendo el distintivo sello romántico de la época, valiosos testimonios visuales sobre personajes, trajes populares, enseres, oficios, alimentos, diversiones, paisajes y arquitectura correspondientes a un espacio temporal bien definido: 1855-1856, fechas de la publicación del libro México y sus alrededores.

Otro de los aspectos extraordinarios de La Moreña radica en ciertas particularidades de su contexto de factura, si se toma en cuenta el control que en esa época ejercía la Academia en relación con los temas pictóricos tratados - como se ha expresado públicamente, el conjunto pictórico es el único vestigio que se conserva completo en el estado de Jalisco de aquella expresión menospreciada en el campo del arte-, aparte de su excelente calidad estética y de oficio; "pocas pinturas del siglo XIX están trabajadas con esa gran calidad" (Montero, comunicación personal, 2009).

La buena preservación de los murales y su historia también es digna de hacerse notar. En primer lugar, la ejecución del programa pictórico deriva de un contexto específico: el encargo del propio dueño de la casa y hacendado de la región, coronel Francisco Velarde, quien tenía la intención de invitar y recibir al recién llegado emperador Maximiliano de Habsburgo, una vez que se impuso el Segundo Imperio en nuestro país. En segundo término, sabemos que desde su edificación hasta hoy en día la Casa de Cultura de La Moreña ha experimentado cambios de uso que han derivado tanto de acontecimientos nacionales como de situaciones particulares (Ramírez 2000ab).

Sobre los primeros cabe mencionar que, a partir de 1867, fecha en la que el presidente Benito Juárez restauró la República en México, se inició una persecución en contra de los simpatizantes del Imperio, entre los cuales se encontraba el coronel Ve- larde, acusado de traición a la patria y fusilado, por lo que subsiguientemente su casa (La Moreña) fue confiscada y puesta a remate. A partir de este momento el inmueble se ha utilizado como casa habitación, taller mecánico, restaurante, bar, gimnasio y salón de fiestas. Finalmente, en 1967, a petición de la propia población de La Barca, el gobierno del estado de Jalisco adquirió la propiedad e instauró en ella una casa de cultura municipal, función que tiene hasta la actualidad y posibilita que un número considerable y creciente de visitantes aprecie sus murales.

Un momento digno de considerar en la historia de estas obras fue la primera intervención hecha por profesionales de la conservación en 1972, proyecto que ejecutó el INAH y también dirigió Montero. Entre los objetos de aquella iniciativa destacó una visión integral que abarcó tanto la restauración de los murales como el aspecto arquitectónico del inmueble. Asimismo, es importante señalar que durante la elaboración del diagnóstico para la fundamentación de este proyecto, Montero expresó su asombro ante el aceptable estado de conservación que presentaban las obras murales, a pesar del abandono en que para entonces se encontraba la casa, condición que atribuyó a la excelente técnica de manufactura con que habían sido ejecutadas.

Lamentablemente, a casi 40 años de la conclusión del primer proyecto de conservación en La Moreña, en el año de 2007 el equipo de restauradores de la ENCRyM-INAH detectó que el paso del tiempo, los diversos usos de la propiedad y algunas intervenciones inadecuadas, posteriores a la iniciativa de 1972, habían generado alteraciones que demeritaban su estabilidad y lectura. Por ello, se decidió empezar una primera temporada de trabajo que se dedicó a optimizar la estabilidad material de las pinturas murales y comprendió de 2007 a 2008. Para el año siguiente se organizó una segunda temporada del proyecto, cuyo fin se encaminó a atender directamente las problemáticas relativas a la imagen de la obra. Las alteraciones identificadas durante el diagnóstico realizado durante esta segunda temporada se tratan a continuación.

\section{Alteraciones presentes en los murales}

Como hemos mencionado, a lo largo de sus más de 130 años de historia, las pinturas de La Moreña han estado sometidas a diferentes condiciones y modificaciones que determinaron su condición a inicios de 2009. Las alteraciones identificadas entonces por el equipo de restauradores de la ENCRYM-INAH correspondían tanto a degradación de materiales constitutivos como a afectaciones en su imagen.

Es importante señalar que, aunque se presentaban algunas alteraciones en la estabilidad material de las pinturas murales, el deterioro se caracterizaba, principalmente, por afectaciones que impedían la cabal lectura y la apreciación de la imagen; generalizadamente, en la presencia de varias capas de suciedad superficial que cubrían los diseños, y el de mayor intensidad, estaba asociado a tres tipos de intervenciones realizadas con posterioridad al proyecto de restauración de 1972, a saber:

- Limpiezas excesivas en los murales habían removido pátinas y veladuras y generado abrasión en la capa pictórica.

- Reintegraciones inadecuadas y éticamente cuestionables —desde gran cantidad de repintes, hasta nutridos virados de tono- demeritaban tanto la estética como la autenticidad documental de las obras murales: por un lado, los repintes se hicieron para cubrir abrasiones generalizadas causadas por el uso y la ocupación del inmueble, pero ocultaron detalles del diseño pictórico; por el otro, nutridos y reintegraciones constituían intentos de disimular errores o evidencias de tratamientos desafortunados, tales como limpiezas excesivas. 
- Aplicación de una serie de capas sobrepuestas de pátina artificial; es decir, barnices coloreados y veladuras que modificaban las tonalidades de la capa pictórica original.

Cabe señalar que los registros escritos sobre estas intervenciones son muy limitados, por lo que se desconocen los materiales empleados en ellas. Con base en lo anterior, no es de extrañar que aunque la propuesta de intervención de esta temporada incluyera acciones de conservación para favorecer la estabilización de la obra, predominantemente se hubiera dirigido a optimizar su imagen a través de tratamientos de restauración, tal y como se describe en la siguiente sección.

\section{Propuesta de intervención}

La propuesta de intervención de la temporada 2009 incluyó los siguientes procesos y especificaciones:

- Control de humedad ascendente en muros.

- Limpieza de suciedad y velos salinos.

- Reposición de resanes.

- Remoción de intervenciones anteriores inadecuadas: repintes, restos de barniz, pátinas artificiales y zonas de nutridos con tonos virados.

- Aplicación de capa de protección.

- Reintegración cromática, que incluiría nutrido ${ }^{1}$ de color en zonas con abrasión y el tratamiento de lagunas pictóricas con técnica de rigattino.

Desde el punto de vista normativo, se determinó que los criterios que privarían en las intervenciones por realizar en las pinturas murales de la Moreña serían:

\footnotetext{
${ }^{1}$ El término nutrido se refiere al proceso de reintegración que busca aumentar la saturación de color, por medio de la técnica de puntillismo en zonas sin diseño, con el fin de optimizar la lectura de la obra.
}

- Respeto a su originalidad en el conjunto de su constitución material, significado histórico y relevancia estética.

- Estabilización material de la obra atendiendo las causas de alteración.

- Eliminación de intervenciones anteriores inadecuadas sin afectar la integridad de cada mural.

- Optimización de su lectura en un equilibrio de mínima intervención, reversibilidad material y distinción de reintegración.

\section{Intervenciones realizadas}

A continuación se reportan las intervenciones realizadas, con señalamiento de los materiales y técnicas utilizados y descripción de los resultados obtenidos:

\section{Control de humedad ascendente en muros}

Como la humedad era una de las principales causas de alteración de las pinturas de La Moreña, se deci-

\begin{tabular}{|c|c|}
\hline \multicolumn{2}{|c|}{$\begin{array}{c}\text { TIPOS DE GELES EMPLEADOS EN LA LIMPIEZA } \\
\text { DE LA PINTURA MURAL* }\end{array}$} \\
\hline Gel & Uso y características \\
\hline $\begin{array}{l}\text { TEA (trietanol amina), } \mathrm{pH} \\
8.5 \text { y } 6.5, \text { y HPMC (hidroxi- } \\
\text { propil metil celulosa) }\end{array}$ & $\begin{array}{l}\text { Sólo se empleó en dos casos específicos: en las baldosa del mu- } \\
\text { ral "La plaza", y para remover graves capas de suciedad en el mural } \\
\text { "La caza del venado", ya que reportó resultados limitados en la } \\
\text { limpieza del resto de los murales. }\end{array}$ \\
\hline $\begin{array}{l}\text { Hexametafosfato de sodio } \\
\text { en suspensión pH } 8.5 \\
\text { y CMC (carboximetil ce- } \\
\text { lulosa) }\end{array}$ & $\begin{array}{l}\text { Muy efectivo para la limpieza de murales con considerables ca- } \\
\text { pas de suciedad y de barnices oxidados, tales como "La visita } \\
\text { del caporal" y "La caza del venado". En el segundo caso, dada } \\
\text { su efectividad, se optó por emplearlo como reemplazo del gel de } \\
\text { TEA, que actuaba de manera limitada y dispendiosa. }\end{array}$ \\
\hline $\begin{array}{l}\text { EDTA (ácido dietilendiami- } \\
\text { no tetra acético } \mathrm{pH} 8.5 \text { y } \\
\text { HPMC }\end{array}$ & $\begin{array}{l}\text { Utilizado de manera puntual, particularmente para la elimina- } \\
\text { ción de velos salinos. Se empleó solamente en los murales "La } \\
\text { ordeña" y "La capilla" ya que su agresividad generaba reblande- } \\
\text { cimiento de la capa pictórica original. }\end{array}$ \\
\hline $\begin{array}{l}\text { NTA (nitriltriacético), } \\
\text { pH } 8.5 \text { y } 6.5, \text { y HPMC }\end{array}$ & $\begin{array}{l}\text { Útil para la eliminación de velos salinos, suciedad y barnices oxi- } \\
\text { dados sobre policromía de personajes, colores blancos del cielo, } \\
\text { verdes de hojas de follaje y detalles de la arquitectura. La efica- } \\
\text { cia de su uso en la mayoría de los murales deriva de su poder } \\
\text { secuestrante: actúa removiendo fácilmente barnices sin generar } \\
\text { alteraciones materiales en la capa pictórica original. Destaca su } \\
\text { desempeño en la eliminación de grandes capas de suciedad en } \\
\text { el mural "La caza del venado". En los casos de "Vendedores in- } \\
\text { dígenas", "El canal de La Viga" y "La portada" se generó una re- } \\
\text { acción secundaria a la limpieza: la formación de velos amarillos } \\
\text { en áreas del cielo, los cuales se trataron con gel de acetona y } \\
\text { alcohol bencílico. }\end{array}$ \\
\hline $\begin{array}{l}\text { *La preparación de los gele } \\
\text { en campo, por }\end{array}$ & $\begin{array}{l}\text { e realizada por el químico Javier Vázquez Negrete (ENCRyM-INAH) o bien, } \\
\text { quipo de trabajo, utilizando las fórmulas de Richard Wolbers. }\end{array}$ \\
\hline
\end{tabular}

FIGURA 6. Tipos de geles empleados en la limpieza de la pintura mural. 
dió construir drenes de aire a nivel del piso original frente a cada mural. Para ello se abrieron zanjas de $18 \mathrm{~cm}$ de profundidad por $35 \mathrm{~cm}$ de ancho, las cuales se rellenaron primeramente con una delgada capa de grazón ${ }^{2}$ que se cubrió con dos niveles de ladrillos. Éstos se unieron y fijaron al suelo con mortero de cal-arena coloreado en rojo. Los espacios vacíos entre los ladrillos se taparon con granzón. Sin duda, la presencia de estos drenes, al generar frentes de secado alternativo, mejorará las condiciones de los murales, por lo que es importante monitorear los resultados obtenidos a dos años de su colocación.

\section{Limpieza superficial}

El objeto de la limpieza fue remover materiales ajenos que impedían una correcta apreciación de la imagen, particularmente suciedad acumulada y velos salinos superficiales. Durante el proceso se emplearon métodos mecánicos y químicos, entre los que destaca el uso de geles de limpieza, los cuales reportaron resultados diferenciados, tal y como se consigna en la siguiente tabla (Figura 6).

Mediante el proceso paulatino de limpieza superficial identificamos de manera más precisa tanto los efectos de deterioro como las problemáticas que había que enfrentar, pues se dimensionó la magnitud y gravedad de los añadidos pictóricos, las áreas de reintegración mal ejecutadas, las capas de pátinas artificiales y las zonas que requerían resane que, debido a capas de suciedad o velos salinos, no eran evidentes antes de ser limpiados.

\section{Eliminación de intervenciones anteriores inadecuadas}

Los procesos utilizados durante este tratamiento incluyeron el uso de diversos solventes orgánicos en estado de gel, cuya acción química fue auxiliada por medios mecánicos. Tanto los efectos de diversos productos

${ }^{2}$ Grava de tezontle.

\section{GELES UTILIZADOS EN LA REMOCIÓN DE INTERVENCIONES ANTERIORES INADECUADAS}

\begin{tabular}{|c|c|}
\hline Gel & Uso y características \\
\hline $\begin{array}{l}\text { Acetona y alcohol bencíli- } \\
\text { co, y carbopol } 934\end{array}$ & $\begin{array}{l}\text { Usado con mucha frecuencia para remover repintes de color } \\
\text { blancos en cielo, capas de grasa verde, reintegraciones, man- } \\
\text { chas en el cielo, barnices oxidados y pátinas artificiales. Aunque } \\
\text { su poder disolvente es considerable, su aplicación en los mura- } \\
\text { les no significó alteraciones en la capa pictórica. Se comprobó } \\
\text { una acción de limpieza efectiva, particularmente en velos color } \\
\text { amarillo. }\end{array}$ \\
\hline $\begin{array}{l}\text { Ácido cítrico, pH 6.5, y } \\
\text { HPMC }\end{array}$ & $\begin{array}{l}\text { Su aplicación permitió remover la suciedad, los barnices oxida- } \\
\text { dos y los velos salinos de murales como "Salto del agua", "Santo } \\
\text { Domingo", "La portada" y "La capilla", particularmente en las } \\
\text { áreas pictóricas de cielos, arquitectura y horizontes. }\end{array}$ \\
\hline $\begin{array}{l}\text { Ácido abiético, pH, 8.5, } \\
\text { y HPMC }\end{array}$ & $\begin{array}{l}\text { Éste resultó ser el único gel eficaz en la remoción de los barnices } \\
\text { oxidados durante la limpieza de las áreas del cielo de "La orde- } \\
\text { ña". No se empleó en otros casos, ya que se provocaba la disolu- } \\
\text { ción del aglutinante de los pigmentos. }\end{array}$ \\
\hline $\begin{array}{l}\text { Ácido deoxicólico, pH 8.5, } \\
\text { y HPMC }\end{array}$ & $\begin{array}{l}\text { Como provocaba la disolución y cambio de tonalidad de pigmen- } \\
\text { tos verdes, se usó únicamente en limpiezas localizadas. }\end{array}$ \\
\hline $\begin{array}{l}\text { *La preparación de los gele } \\
\text { en campo, por e }\end{array}$ & $\begin{array}{l}\text { realizada por el químico Javier Vázquez Negrete (ENCRyM-INAH) o bien, } \\
\text { uipo de trabajo, utilizando las fórmulas de Richard Wolbers. }\end{array}$ \\
\hline
\end{tabular}

FIGURA 7. Geles utilizados en la remoción de intervenciones anteriores inadecuadas.

empleados en las intervenciones anteriores inadecuadas como las particularidades pictóricas de los murales requirieron soluciones específicas, tal y como lo resume la tabla subsecuente (Figura 7).

En algunos casos tuvieron que resolverse efectos secundarios derivados de la aplicación de ciertos solventes, por ejemplo, como ya lo hemos mencionado (Figura 6), para el caso del gel de NTA. Otras zonas presentaron una pérdida de saturación de tono de color, comúnmente denominado pasmado, que impedía observar y comparar el nivel de limpieza, identificar manchas puntuales $y$, sobre todo, contemplar la unidad visual de los murales. Para solucionar este efecto, todas las zonas se saturaron con emulsión de xileno-agua y posteriormente se removió con gaso- lina cualquier resto de gel, proceso indispensable previo a la aplicación de un barniz para restablecer la saturación cromática de las obras.

Es importante mencionar que la eliminación de intervenciones se hizo sólo en las zonas donde no existían riesgos de afectar la estabilidad o integridad de la capa pictórica, o bien en aquellas otras donde este tratamiento no hubiera constituido un cambio positivo para su lectura, ya que su eliminación hubiera dejado al descubierto grandes extensiones de áreas con abrasión, lo que hubiera implicado muchas horas de trabajo para nutrir de color, como fue el caso de algunos cielos que se encontraron repintados hasta en $60 \%$ de su superficie.

Cabe señalar que tanto las grandes dimensiones de las áreas por 


\section{REGISTRO DE LOS RESULTADOS DEL PROCESO DE LIMPIEZA EN LOS MURALES AL TÉRMINO DE LA TEMPORADA 2009}

\begin{tabular}{|c|c|c|}
\hline $\begin{array}{c}\text { Murales cuya limpieza } \\
\text { fue terminada }\end{array}$ & $\begin{array}{c}\text { Murales con limpieza } \\
\text { parcial }\end{array}$ & $\begin{array}{c}\text { Murales sin limpieza } \\
\text { parcial }\end{array}$ \\
\hline $\begin{array}{l}\text { Quince murales: "Santo } \\
\text { Domingo", "El canal de La } \\
\text { Viga", "El jarabe", "La proce- } \\
\text { sión", "El columpio", "La por- } \\
\text { tada", "La lavandera y vende- } \\
\text { dora de patos", "La capilla"; } \\
\text { "La ordeña", "Los chinacos", } \\
\text { "Los vendedores indígenas", } \\
\text { "Los niños con ratón y palo- } \\
\text { ma", "El tianguis", "La plaza" } \\
\text { y "Salto del agua". }\end{array}$ & $\begin{array}{l}\text { "La visita del caporal", con } \\
20 \% \text { de avance: sólo faltan } \\
16 \mathrm{~m}^{2} \text { por limpiar. "El jari- } \\
\text { peo", con } 95 \% \text { de avance, lo } \\
\text { que significa que sólo falta } \\
0.5 \mathrm{~m}^{2} \text { por limpiar. }\end{array}$ & $\begin{array}{l}\text { "Escena romántica", con una } \\
\text { extensión de } 20 \mathrm{~m}^{2} \text {. "La caza } \\
\text { del venado", con una super- } \\
\text { ficie de } 20 \mathrm{~m}^{2} \text {. }\end{array}$ \\
\hline $\begin{array}{l}\text { Superficie toral de limpieza: } \\
370.3 \mathrm{~m}^{2}\end{array}$ & \multicolumn{2}{|c|}{ Faltan por limpiar: $56.5 \mathrm{~m}^{2}$} \\
\hline
\end{tabular}

FIGURA 8. Registro de los resultados del proceso de limpieza en los murales al término de la temporada 2009.

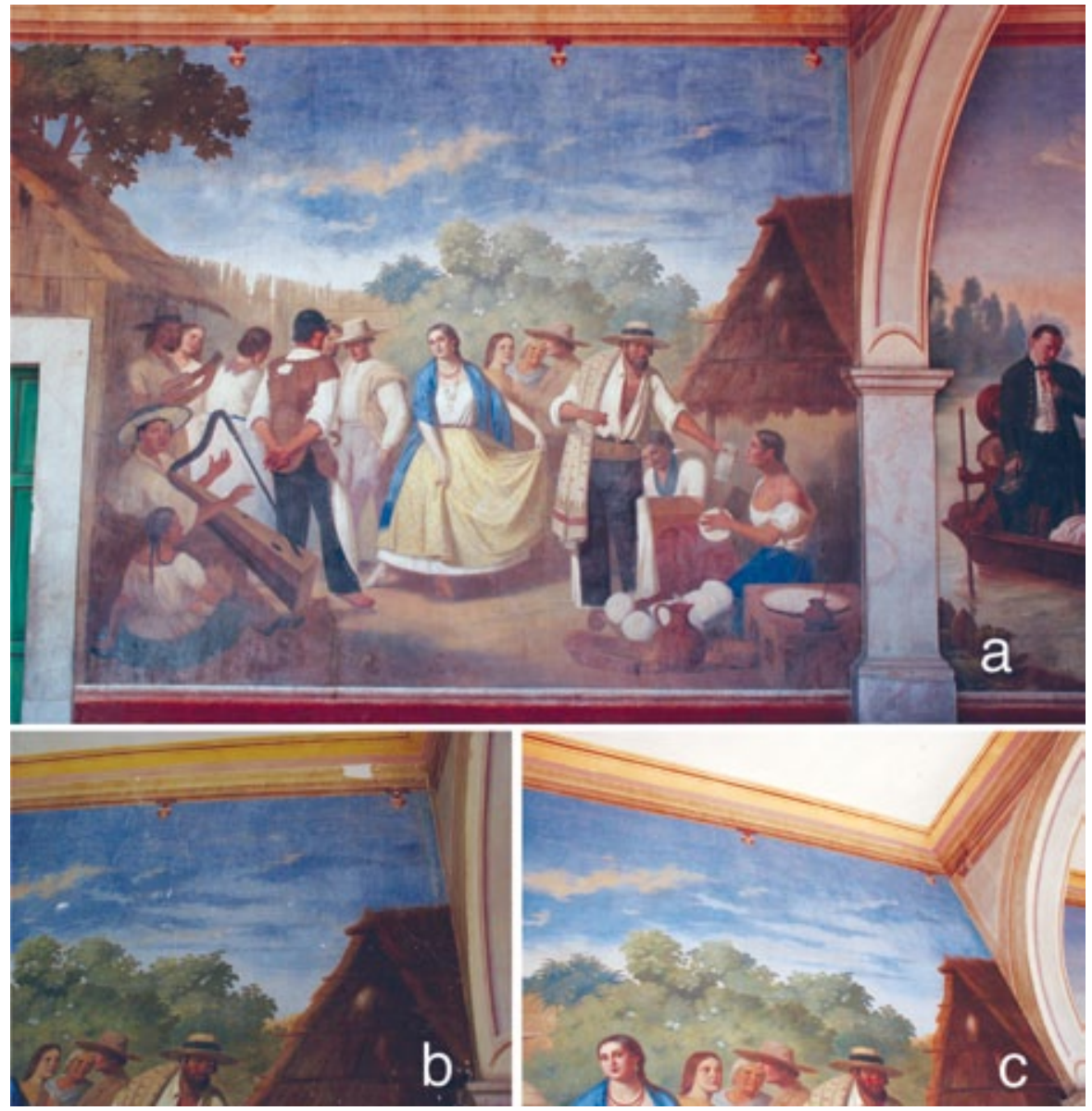

FIGURA 9. a) Mural "El jarabe" (Fotografía: Gerardo Ruiz Hellión, 2008: cortesía: ENCRyM-INAH). b) Detalle antes del proceso; c) Detalle después de la limpieza y reintegración (Fotografía: Gisela García y Liliana Alfaro, 2009; cortesía: Proyecto de Conservación de La Moreña, ENCRyM-INAH). intervenir como la experimentación para encontrar los métodos más adecuados para hacerlo implicaron que la fase de limpieza requiriera más tiempo del planeado originalmente. No obstante, al término del proyecto 2009 se había logrado limpiar por completo quince murales y sólo dos de manera parcial, ubicados en los pasillos. El avance de las zonas limpiadas corresponde aproximadamente a $85 \%$ de la superficie de obra mural de la casa de La Moreña. En la siguiente tabla (Figura 8) se exponen los resultados al término de la temporada de 2009.

\section{Resane}

El resane de faltantes de enlucido fino se realizó con morteros finos de cal y polvo de mármol en proporciones $1: 3$.

\section{Aplicación de capa de protección}

Con el fin de sellar los resanes, saturar el tono de las capas pictóricas, aislar las reintegraciones y brindar protección, se aplicó una película a base de barniz dammar al 5\% en thinner. El resultado fue satisfactorio especialmente en aquellas zonas que presentaban pasmados superficiales, ya que se logró revertir el problema de saturación cromática.

\section{Reintegración cromática}

La reintegración cromática de los murales se realizó con pinturas al barniz —es decir, pigmentos naturales suspendidos en una base de resina dammar disuelta en un vehículo de xileno, lo cual garantiza su reversibilidad en una obra al óleo-, mientras las zonas que presentaban abrasión y en interrupciones de tamaño mínimo se nutrieron con puntillismo; en aquellas lagunas de mayor tamaño se empleó la técnica de rigattino, con el fin de promover que el observador pueda hacer una diferenciación entre el original y el área intervenida. También se aplicaron veladuras con pinturas al barniz en las zonas de pér- 

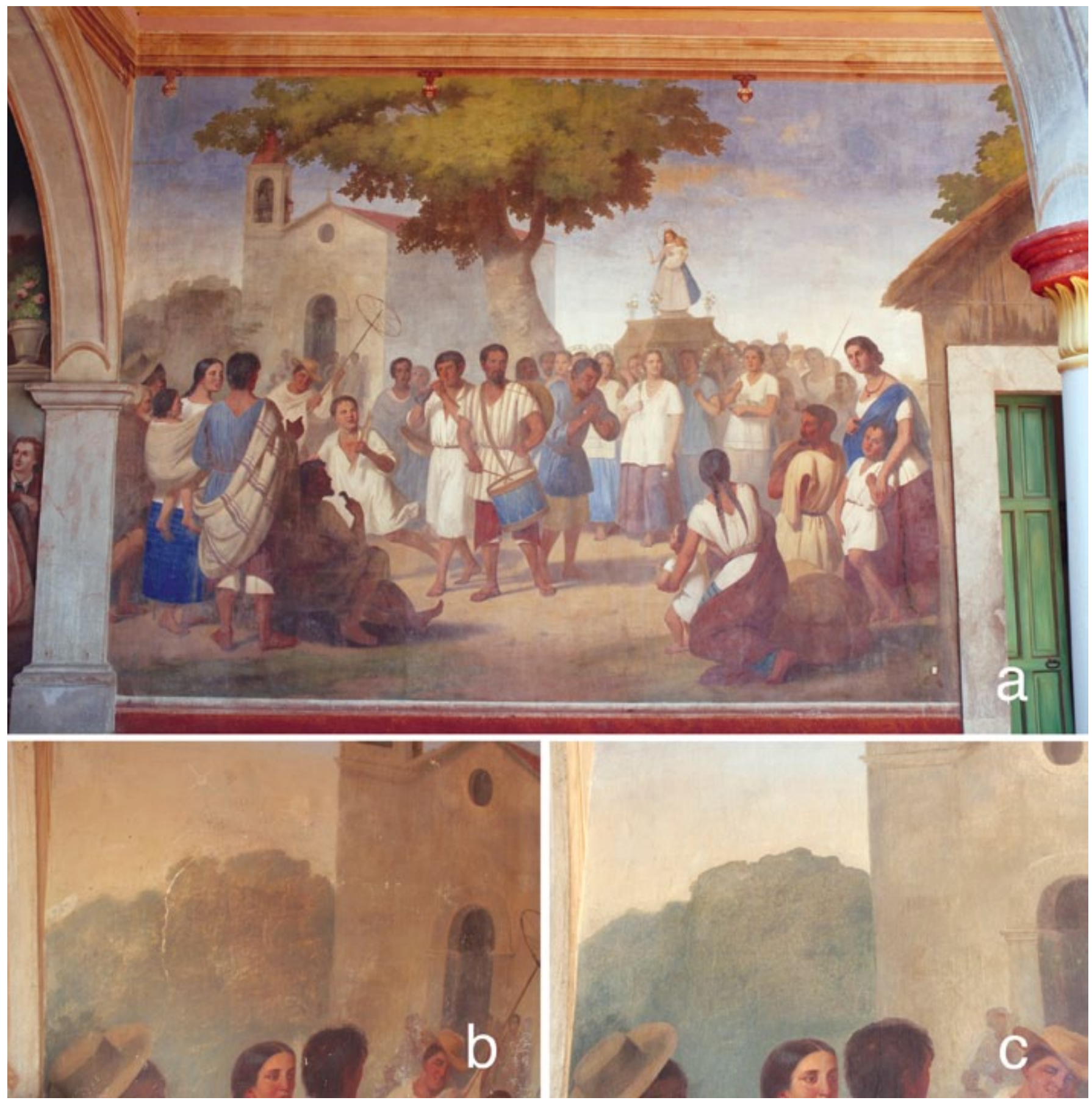

FIGURA 10. a) Mural "La procesión" (Fotografía: Gerardo Ruiz Hellión, 2008: cortesía: ENCRyM-INAH). b) Detalle antes del proceso; c) Detalle después de la limpieza y reintegración (Fotografía: Liliana Alfaro, 2009; cortesía: Proyecto de Conservación de La Moreña, ENCRyM-INAH).

dida de pátina natural, con el propósito de homogenizar la apariencia final de la obras; esto permitió que recobraran saturación e intensidad y optimizó considerablemente la lectura de los diseños.

Al término de la intervención de 2009 se logró la reintegración cromática de cinco murales completos (aproximadamente, 40\% del total de la obra mural): "Santo Domingo", "El canal de La Viga", "El jarabe" (Figura 9), "La procesión" (Figura 10) y "La portada"; la reintegración parcial de cuatro murales: "El columpio" $(90 \%$ de avance), "Los chinacos" (70\%), "Salto del agua" (70\%) (Figura 11) y "La plaza" (30\%).

\section{Reflexiones finales}

La segunda temporada de restauración de las pinturas murales de La Moreña significó un reto de significativas magnitudes para los restauradores que estuvimos involucrados como parte del equipo de trabajo, ya que se buscó restablecer los valores histó- 


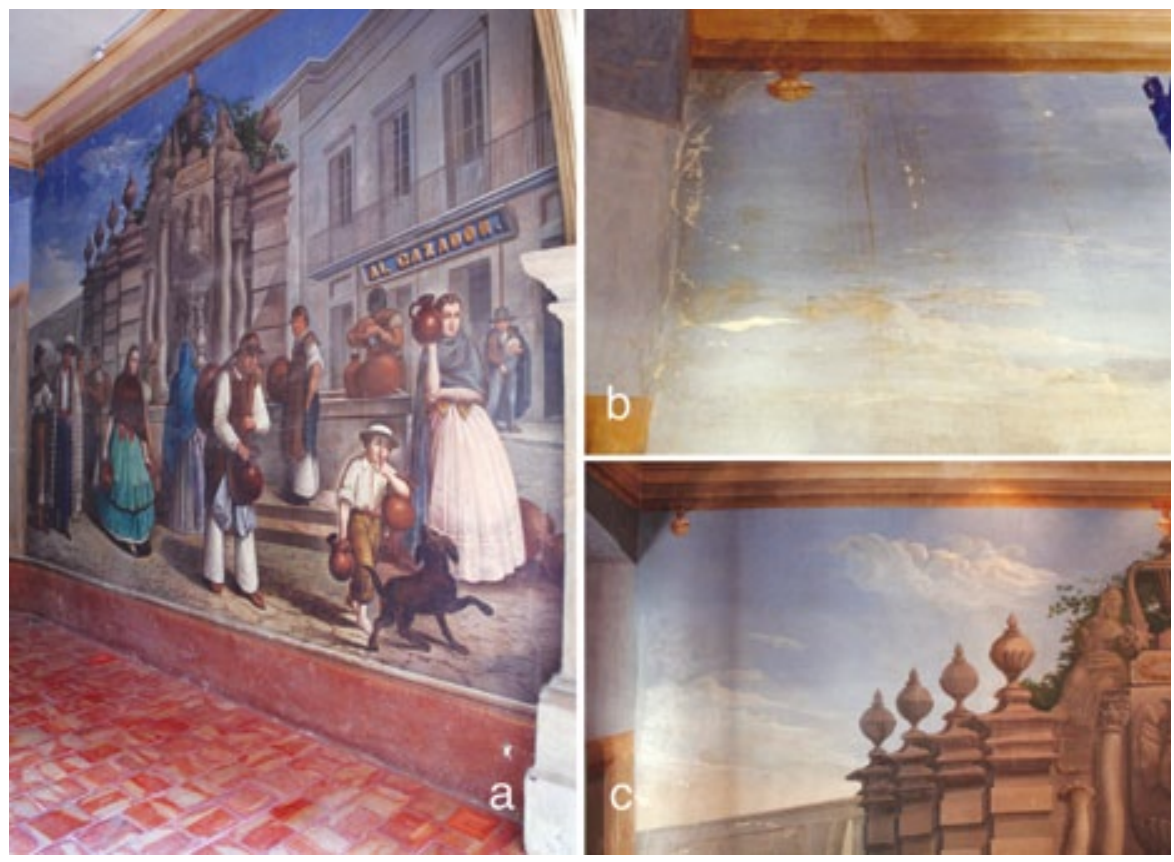

FIGURA 11. a) Mural "Salto del agua" (Fotografía: Gerardo Ruiz Hellión, 2008: cortesía: ENCRyMINAH). b) Detalle antes del proceso; c) Detalle después de la limpieza y reintegración (Fotografía: Liliana Alfaro, 2009; cortesía: Proyecto de Conservación de La Moreña, ENCRyM-INAH).

ricos y, principalmente, estéticos de una obra de gran relevancia en México, la cual presentaba una compleja problemática de deterioro derivada de condiciones ambientales específicas, diversos cambios de uso en el inmueble que la contiene y una serie de desafortunadas intervenciones previas. A lo largo de este reporte ya se han descrito los procesos realizados, su desarrollo y sus resultados. Por tanto, quisiéramos aprovechar este espacio para exponer tres reflexiones finales derivadas de nuestra experiencia en una iniciativa enriquecedora y ardua de 10 meses de trabajo.

La primera de ellas se refiere al proceso de limpieza y remoción de intervenciones anteriores. Es indudable que éstas significaron un interesante desafío, ya que plantearon la necesidad de remover barnices oxidados, capas de suciedad, velos salinos y repintes, y de realizar reintegraciones cromáticas sobre una técnica oleosa ya afectada. De ahí que el desarrollo de los tratamientos se balanceara entre el imperativo de conservar al máximo la estabilidad material de la obra y el requerimiento de recuperar la composición y el ma- nejo cromático de su imagen. Lograr este equilibrio no fue fácil: demandó una mezcla de técnica y destreza.

Desde el punto de vista técnico, el equipo de restauradores decidió hacer uso de geles, materiales con los que la ENCRyM-INAH ya contaba con una serie de experiencias positivas en la limpieza y eliminación de intervenciones anteriores en pintura al óleo (Madrid Alanís 2010). Sin embargo, su uso resultó complejo para nosotros, ya que cada mural se comportó como un universo único en términos de eficiencia tanto de remoción como de la reacción de sus materiales constitutivos. Así, la experiencia y el criterio de los restauradores se volvió determinante en la intervención: se valoró cada caso para decidir, por un lado, lo que era necesario remover para rescatar la imagen y, por el otro, el nivel de limpieza al que se quería llegar y los propios efectos del tratamiento. Asimismo, se debe considerar que nuestra experiencia y resultados sobre el comportamiento del uso de geles de limpieza en la pintura mural de La Moreña podrán ser útiles y enriquecedores para futuras intervenciones, al constituirse en referentes que deberán valorarse y evaluarse para cada caso en particular.

Nuestra segunda reflexión es relativa al proceso de reintegración cromática. Es obvio que éste se desarrolló como complementario a la limpieza, ya que esta última había desvelado fallas y errores derivados de intervenciones anteriores, que sin ningún criterio habían aplicado repintes, pátinas, nutridos y reintegraciones que estaban mal ejecutadas 0 trataban de ocultar malos resultados. Ante esta problemática fue necesario seguir criterios tanto responsables como pragmáticos. Si bien no era factible ni ético reintegrar la mitad de la superficie de la obra plástica, se buscó optimizar su lectura sin afectar su autenticidad pictórica; la observación detallada llevó a cuestionamientos sobre grados de reintegración que se complementaron tanto por exámenes auxiliados con luz UV como por asesorías guiadas por el ojo crítico de restauradores con amplia experiencia, entre ellos Sergio Montero, Liliana Giorguli y Gisela García.

Nuestra tercera consideración se refiere a los efectos últimos de nuestras intervenciones como restauradores: la optimización de la lectura tuvo un efecto inmediato, al atraer la atención de los habitantes de La Barca, quienes empezaron a expresar un sentimiento de orgullo sobre el patrimonio pictórico que heredaron del coronel Velarde. De esta manera, la disciplina de la restauración cumple con un objetivo adicional de orden social, cuyos efectos son dignos de meditación.

\section{Agradecimientos}

Agradecemos a Gerardo Hellión y Oscar Ibarra (AMBYM-INAH) y al Comité Editorial de la revista Intervención su apoyo en la publicación de este artículo.

\section{Referencias}

Castro, Casimiro

2010 "Casimiro Castro", América exó- 
tica. Panorámicas, tipos y costumbres del siglo XIX, documento electrónico disponible en [http://www.lablaa.org/ blaavirtual/exhibiciones/america_exotica/biografias/casimirocastro.htm], consultado en enero del 2010.

Gutiérrez, Juana

2000 "Tradición, estilo y escuela en la historiografía del arte virreinal mexicano. Reflexión en dos tiempos", en Jaime Soler Frost (ed.), Los pinceles de la historia. El origen del reino de la Nueva España, 1680-1750, México, Munal/IIE-UNAM, 58-85.

INAH

2009 "Patrimonio excepcional de Ja- lisco", Pintura mural costumbrista, documento electrónico disponible en [http://www.inah.gob.mx/index.php/ especiales/165-pintura -mural-costumbrista-], consultado en enero del 2010.

Madrid Alanís, Yolanda

2009 "La restauración de pinturas sobre tabla del siglo XVı pertenecientes al retablo mayor de Coixtlahuaca, Oaxaca", Intervención 1 (1): 52-59.

Montero Alarcón, Sergio Arturo 1991 La restauración de las pinturas murales de la casa de La Moreña, México, ENCRyM-INAH.

Ramírez, Fausto 2000a "La historia disputada de los orígenes de la nación y sus recreaciones pictóricas a mediados del siglo XIX", en Jaime Soler Frost (ed.), Los pinceles de la historia. De la patria crioIla a la nación mexicana, 1750-1860, México, Munal/IIE-UNAM, 230-248.

2000b “La 'restauración' fallida: la pintura de historia y el proyecto político de los conservadores en el México de mediados del siglo XIX", en Jaime Soler Frost (ed.), Los pinceles de la historia. De la patria criolla a la nación mexicana, 1750-1860, México, Munal/IIE-UNAM, 203-229.

\section{Resumen}

Las pinturas de La Moreña, ubicadas en la actual casa de cultura de la comunidad de La Barca, en el sur de Jalisco, constituyen obras de gran relevancia para la historia política y artística de nuestro país. Para atender la compleja problemática de deterioro presente en estos murales, en el 2007 la ENCRyM-INAH inició la ejecución de un proyecto de conservación y restauración dirigido por el profesor Sergio Arturo Montero Alarcón. En esta contribución se reportan las intervenciones correspondientes a la segunda temporada del proyecto, correspondiente al año 2009, cuyos objetivos se centraron en el tratamiento de la imagen. Se exponen los desafíos, recursos, procedimientos y resultados involucrados en la atención de alteraciones que afectaban tanto la autenticidad como la lectura de las escenas murales, durante la que se puso especial énfasis en explorar el uso de geles para limpieza y eliminación de reintegraciones éticamente cuestionables. Se concluye con una serie de reflexiones sobre la labor del restaurador que derivan de experiencia única adquirida durante una ardua labor de 10 meses dirigida a la restauración de las pinturas de La Moreña.

\section{Palabras clave}

Pintura mural al óleo, siglo XIX, pintura costumbrista mexicana, restauración, geles, limpieza.

\section{Abstract}

La Moreña's wall paintings, housed in a building now used as a cultural centre for the community of La Barca in southern Jalisco, are very relevant to Mexican political and artistic history. In 2007, the ENCRyM-INAH started a restoration project, under the direction of Professor Sergio Montero, to attend to the complex deterioration problems of the murals. This contribution reports on the conservation and restoration processes carried out during the second period of the project, in 2009, which were focused on the recovery of the images. The challenges, resources, procedures, and results involved in the treatment of the alterations affecting both the authenticity and readability of the mural scenes are described, with particular emphasis on the exploration of the use of gels for cleaning and the elimination of ethically questionable visual re-integrations. This paper concludes with a series of thoughts on the restorer's role, all of which derived from the unique experience acquired during this 10-month period of hard work restoring La Moreña's mural paintings.

\section{Key words}

Mural oil painting, Nineteenth Century, paintings of Mexican customs, restoration, gels, cleaning.

Título en inglés: The restoration of La Moreña's wall paintings, La Barca, Jalisco: interventions, partial results, and reflections on an ENCRyM-INAH project 